\title{
Exploratory Clinical Trials: Implementation Modes \& Guidelines, Scope and Regulatory Framework
}

\author{
Alain Francillon ${ }^{1}$, Gisèle Pickering ${ }^{2}$, Chantal Belorgey ${ }^{3}$ and the participants in Round Table $N^{\circ} 2$, Giens XXIV ${ }^{\star}$ \\ 1 Novartis, Rueil-Malmaison, France \\ 2 Centre de Pharmacologie Clinique, CHU, Clermont-Ferrand, France \\ 3 Afssaps, Unité Essais Cliniques, Saint-Denis, France
}

Text received 15 october 2008; accepted 20 november 2008

\section{Keywords: \\ drugs; \\ guidelines; \\ recommendations; \\ exploratory clinical \\ trials; \\ early selection \\ of drug}

\begin{abstract}
The working group focused on defining exploratory trials on medicinal products and developing recommendations for their implementation in France (notably concerning non-clinical requirements, the pharmaceutical quality of the investigational medical product and the conditions under which this type of clinical trial may be performed).

To this end, the working group took account of existing guidelines (notably those in the USA and Belgium) and a draft revision of the ICH M3 guideline.

Exploratory trials are clinical trials performed early in Phase I, prior to dose escalation and safety and tolerability trials. These trials are de facto first-in-man studies but lack a therapeutic or diagnostic goal and do not seek to establish the maximum tolerated dose (MTD). The objective is to answer precise questions which condition the continuation or suspension of the drug's development program. Exploratory trials include a small number of patients or healthy subjects and expose them (over a short period of time) to a low dose of an investigational medicinal product.

The draft revision of M3 describes five approaches (two involving microdoses and three with pharmacological doses).

The group's main recommendations can be summarized as follows:

- An exploratory trial may be performed when it is (i) justified, (ii) useful for product development and (iii) consistent with prerequisites.

- The pharmaceutical dossier should take account of the low quantity of product available, the short period of product administration and the low doses used. Good Manufacturing Practices can be adapted accordingly.

- The non-clinical dossier should also be adapted to suit the development phase and particular features of product use. In this respect, the group has commented on the recommendations in the draft revision of M3.

- The protocol must be designed to provide answers to a set of specific, pertinent questions concerning this administration phase - particularly on choice of the initial dose, the size of the dose escalation and the rules for subject withdrawal and trial suspension.

- In general, so-called "vulnerable" populations should not be involved in this type of trial, apart from duly justified exceptions.

- The group considered that approaches 3 to 5 should only apply to a medicinal product intended for treatment of a severe or rare disease or a condition with significant unmet medical needs.

- Pre-filing at the Afssaps (the French Agency for Healthcare Product Safety) is recommended, notably for approaches using pharmacological doses.
\end{abstract}

It has been estimated that only 8 to $10 \%$ of the investigational drugs currently entering Phase I clinical development will obtain

\footnotetext{
* For a list of participants, see the end of the article.
}

marketing authorization (5\% for cancer drugs). ${ }^{[1,2]}$ This very low success rate has been attributed to several causes: the lack of animal models that accurately predict the efficacy and toxicity of new molecular entities, a lack of efficacy, toxicity, inappropriate 
pharmacokinetics, the growing complexity of clinical trials (involving molecular targets and cutting-edge techniques), the lack of biomarkers (particularly in oncology), high resource use (in terms of cost, number of patients and professional resources). The main steps in the lengthy clinical development process (safety, tolerability, efficacy and therapeutic benefit) have hardly changed over the last 35 years, despite the availability of new tools. ${ }^{[3]}$ It has been suggested that the ability to answer a certain number of critical questions concerning a molecule (mechanism of action, targets, etc.) very early in the development process would mitigate the risk of project discontinuation in Phase III. ${ }^{[4]}$ Early selection (notably via the use of "exploratory trials") would help focus efforts on the most promising molecules and accelerate the provision of access to therapeutic innovations.

\section{Introduction}

Few trials of this type have been performed so far in France. If the country is to remain attractive for clinical development programs, it is important that this category of study can be performed in French centers and under conditions that ensure safety and quality. Hence, the working group's objective was to specify a framework for these trials and develop concrete recommendations and proposals.

The working group focused on defining exploratory trials and developing recommendations for their implementation in France, notably concerning non-clinical requirements, the pharmaceutical quality of the investigational medicinal product (IMP) and the conditions under which this type of clinical trial may be performed. To this end, the working group took account of existing guidelines (notably those of the US Food and Drug Administration $^{[4]}$ and some European Union member states ${ }^{[5,6]}$ and the forthcoming version of the ICH M3 guideline. ${ }^{[7]}$

\section{Definition of an "exploratory trial"}

To avoid confusion, it is preferable to refer to an "exploratory trial" rather than use the ambiguous term "Phase 0 trials". Exploratory trials are clinical trials performed early in Phase I, prior to dose escalation and safety and tolerability trials. These trials are de facto first-in-human studies but lack a therapeutic or diagnostic goal. Furthermore, they seek to specify the IMP's pharmacokinetics and/or pharmacology rather than to establish (as in conventional Phase I trials) the maximum tolerated dose (MTD). The objective is to answer specific questions which condition the continuation or suspension of the candidate drug development program. For example, an IMP can be eliminated very early on if exploratory trials reveal poor pharmacodynamic and/or pharmacokinetic properties (rapid clearance, low bioavailability, absence of effect on the target, etc.).

These trials feature a small number of patients or healthy subjects exposed over a short period of time to a low dose of an investigational medicinal product. Exploratory trials are not substitutes for conventional Phase I trials. An exploratory trial is only performed when it is a justified step, is useful in product development, complies with prerequisites and ensures the safety of the participants.

The working group suggested a number of limitations. Exploratory trials should not involve compounds which present risk factors by virtue of their mode of action, the nature of the target or the characteristics of the animal models. ${ }^{[8]}$ Likewise, the working group did not take account of exploratory trials for cell and gene therapy products. Use of exploratory trials is only justified when the benefit/risk ratio in the animal is high. In general, so-called "vulnerable" populations should not be involved in this type of trial, apart from duly justified exceptions.

In oncology, the exploratory seems to be inappropriate for cytotoxic agents with a narrow therapeutic index, those with intermittent, intravenous administration, those which do not correspond to a well-defined pharmacodynamics trial and, lastly, those for which the mechanism of action has not been unambiguously established.

\section{Approaches for exploratory trials and preclinical data}

The draft revision of the ICH M3 guideline ${ }^{[7]}$ describes five approaches, including two that use microdoses (objective: receptor occupancy and biodistribution) and three with pharmacological doses as a single dose or with up to 14 days of repeated dosing [objective: pharmacodynamic activity (PD) and/or pharmacokinetics (PK, PK/PD)] (Table I).

The group considered that approaches 3 to 5 should only apply to medicinal products intended for treatment of a rare disease or a condition with significant medical needs.

\section{1. Guidelines on the pharmaceutical quality of investigational medicinal product other than biologicals}

The specification covers substances only available in very small amounts and which are administered at a very low dose and for a short duration but which have a characterized active substance and have undergone at least basic formulation development. 
Table I.

\begin{tabular}{|c|c|c|c|}
\hline & Approach & Preclinical requirements & The group's comments \\
\hline 1 & $\begin{array}{l}\text { Microdose, } \\
100 \mu \mathrm{g}\end{array}$ & $\begin{array}{l}\text { Extended single dose toxicity } \\
\text { study } \\
\text { in } 1 \text { species }\end{array}$ & $\begin{array}{l}\text { Approach already in place and being used. } \\
\text { Genotoxicity not necessary }\end{array}$ \\
\hline 2 & $\begin{array}{l}\text { Microdose, } \\
5 \times 100 \mu \mathrm{g}\end{array}$ & $\begin{array}{l}\text { 7-day toxicity study } \\
\text { in } 1 \text { species }\end{array}$ & $\begin{array}{l}\text { Toxicity study to be performed, using the intravenous route and the clinical route } \\
\text { or the clinical route only. } \\
\text { Genotoxicity: Ames test to be performed, if an in silico evaluation of the } \\
\text { structure-activity relationship is positive }\end{array}$ \\
\hline 3 & $\begin{array}{l}\text { Single pharmacologi- } \\
\text { cal dose }\end{array}$ & $\begin{array}{l}\text { Extended single dose toxicity } \\
\text { study in } 2 \text { species } \\
\text { Genotoxicity study }\end{array}$ & $\begin{array}{l}\text { The objective is a PK, PD or PK/PD study for a single dose. } \\
\text { The maximum of half the NOAEL seems to be high and could not be acceptable, } \\
\text { since that would be a Phase I dose. }\end{array}$ \\
\hline 4 & $\begin{array}{l}\text { Single dose or repeated } \\
\text { dose for up to } 14 \text { days }\end{array}$ & $\begin{array}{l}\text { 2-week toxicity study in } 2 \\
\text { species } \\
\text { Genotoxicity study } \\
\text { Safety pharmacology } \\
\text { PK }\end{array}$ & $\begin{array}{l}\text { Detailed animal kinetics essential for extrapolating the clinical PK on the basis } \\
\text { of the PK in animals. } \\
\text { The maximum safety margin to be achieved is to be defined on the basis of the } \\
\text { pharmacological, safety and toxicological results }\end{array}$ \\
\hline 5 & & & This model implies pharmacological activity for a dose far below the toxic dose \\
\hline
\end{tabular}

PK: pharmacokinetics; PD: pharmacodynamics; NOAEL: the "no observed adverse effect level" (dose lacking a toxic effect in the animal); Safety margin: ratio of exposure in the animal at the NOAEL/exposure in man at the clinical dose, where exposition is measured via AUCss or Cmaxss values; AUC: area under the curve (plasma concentration); AUCss: steady-state AUC; Cmaxss: maximum steady-state plasma concentration.

For approaches 1 and 2 (microdoses), the active substance should be characterized on the basis of research data, with the synthetic route having been described on the laboratory scale. A theoretical risk analysis on exposure to impurities should be performed, notably with respect to the administered concentration. Lastly, methods for assaying the active substance should be appropriate, with a description of the critical aspects of stability. For the end product, a specific approach will be required for sterile products (analysis of container-contents compatibility, description of the critical aspects of solubilization and crystallization and validation of the sterilization process). For approaches 3 to 5, the Phase I prerequisites should apply. ${ }^{[9]}$

In terms of Good Manufacturing Practice, it appears possible to develop more flexible quality requirements for exploratory trials using approaches 1 and 2; for these microdose trials, the group suggests using the guide to Good Preparation Practices issued by the Afssaps ${ }^{[10]}$ as a reference.

\subsection{Radiopharmaceuticals}

The previous remarks apply to cold products. For radiolabeled products, French regulations require specific administrative authorizations. Guidelines have been suggested at a European level. ${ }^{[11]}$

\subsection{Non-clinical prerequisites}

The group reviewed in detail and commented on the nonclinical prerequisites (in terms of toxicity/genotoxicity/safety pharmacology) mentioned in the draft revision of the ICH M3 guideline $^{[7]}$ for each approach. It emphasized that the toxicology studies (including toxicokinetic studies) and safety pharmacology studies should comply with Good Laboratory Practices. The comments are summarized in Table I.

The single-dose clinical trial must have ended before the repeated-dose clinical trial starts.

\section{Clinical trial performance}

These trials must be performed under the same conditions as current first-in-human trials, in compliance with EMEA (European Medicines Agency) and Afssaps recommendations, ${ }^{[8,12]}$ and notably at specifically authorized research sites. Some trials may require particular technical facilities, a particular investigator qualification and/or the involvement of a pharmacologist.

For a multicenter trial, it is necessary to justify and organize inter-center coordination and real time transmission of information.

Furthermore, the study protocol should describe and justify the frequency of and procedures for drug administration (intervals between the subjects, wash-out periods, number of subjects to whom the IMP is administered on the same day). Several IMPs should not be administered simultaneously or in rapid succession in the same patient/subject in a given trial, except when justified on a case-by-case basis.

The choice of the doses administered and any repeated dosing should be justified. It could be suggested that in any event, the 
dosing should not exceed $1 / 10^{\text {th }}$ the NOAEL exposure or (for biological products) the MABEL (minimum anticipated biological effect level) exposure.

The information sheet and the consent form for healthy subjects or patients should be similar to that used in Phase I trials and should notably specify the absence of a therapeutic objective, the absence of individual benefit ${ }^{[13]}$ and the level of risk evaluated, depending on the approaches 1 through 5 .

Rules for discontinuing a clinical trial have been defined: the trial/dosing should be stopped as soon as the objective defined in the protocol has been achieved or if it is clear that the said objective cannot be achieved. For microdoses (approach 1 or 2), any sign of intolerability is unacceptable. For the other approaches ( 3 to 5), the discontinuation rules will be defined in the protocol and will include any clinical or paraclinical signs other than those related to the defined trial objective. ${ }^{[8,12]}$

\section{1. Validity of the evaluation criteria and methods used in exploratory clinical trials}

This is an essential requirement. In general, the analytical methods used for evaluation should be relevant and should use validated criteria (in terms of repeatability, sensitivity, variability and robustness). Several authors at the National Cancer Institute ${ }^{[3,14,15]}$ thus recommend the use of two different tests for evaluating a substance's mechanism of action on a target. This recommendation appears reasonable, notably when the relation PK/PD has not yet been explored or in the absence of an established relationship.

This strong evaluation criterion (a PD trial) will receive its first validation in man and could thus be used in subsequent studies to monitor target modulation. This upstream PK/PD information could (in oncology trials) enable subsequent optimization of Phase I dose escalation techniques.

\subsection{Populations}

The choice of patients or healthy subjects should be explicitly justified. ${ }^{\left[{ }^{8,12]}\right.}$ The number of subjects/patients must be low. Very generally, exploratory trials should not be applied to pediatric situations, except when duly justified. Likewise, exploratory trials should not involve other so-called "vulnerable" populations.

\subsection{Preparation of the clinical trial authorization application}

The fact that the trial has been classified as an exploratory study should be clearly mentioned in the protocol, the letter and the authorization clinical trial application form. Pre-filing with the Afssaps is advisable, notably for approaches 3 to 5 ( $c f$. the pre-filing procedure on the Afssaps website). Regarding filing to ethics committee (CPP), a CPP-sponsor-investigator dialog is encouraged.

\section{Conclusions}

Exploratory clinical trials seek to answer critical questions concerning a molecule well upstream, before the start of a full clinical development project.

Exploratory trials are possible in France. The Afssaps recommends pre-filing notably for type 3 to 5 exploratory trials (with anticipated pharmacological activity).

The group has proposed conditions for application of $\mathrm{ICH}$ M3, thus opening the way to supervised implementation of this type of clinical trial.

\section{Participants}

Michel Abiteboul (Quintiles), Bernard Bégaud (Département de Pharmacologie, CHU Pellegrin Carreire, Bordeaux), JehanMichel Behier (MSD Chibret), Chantal Belorgey (Afssaps), Bénédicte Chauvin (Novartis), Antoine Cournot (Thérapharm), Rémy Defrance (Pfizer), Jean-Paul Demarez (Pierre Fabre Médicaments), Élisabeth Devilliers (Fédération Hospitalière de France), Vincent Diebolt (GIP CeNGEPS), Bertrand Diquet (Pharmacologie, CHU Larrey, Angers), Yves Donazzolo (OPTIMED Clinical Research), Muriel Echemann (Afssaps), Alain Francillon (Novartis), Christian Funck-Brentano (Pharmacologie, Faculté de Médecine Pitié Salpétrière, Paris), Patrick Genissel(IRI Servier), Nadine Houedé (Institut Bergonié, Bordeaux), Jean-Marc Husson (European Diploma in Pharmaceutical Medicine/Eudipharm, Paris), Philippe Lefevre (Afssaps), Isabelle Macquin-Mavier (Pharmacologie Clinique, Hôpital Henri Mondor, Créteil), Brigitte Marchenay (Roche), Christine Marey (Science Union, les Laboratoires Servier), Laurence Negres-Pages (LN Pharma), Gisèle Pickering (Pharmacologie Clinique, CHU Clermont Ferrand, Clermont-Ferrand), Séverine Pitel (Pharmacologie, CHU Timone, Marseille), Valérie Plattner (Direction de la Recherche Clinique et de l'Innovation, CHU Lyon, Lyon), Christine Roy (Sanofi Aventis Research and Developpment), Michel Sibille (Centre Hospitalier Lyon Sud, Pierre Bénite), Nicolas Simon (Faculté de Médecine, Marseille), Claire Thalamas (CHU de Toulouse, Hôpital Purpan, Toulouse), Dominique Tremblay (Afssaps), Tony Waegemans (LFB). 


\section{References}

1. Marchetti S, Schellens JHM. The impact of FDA and EMEA guidelines on drug development in relation to Phase 0 trials. Br J Cancer 2007; 97: 57781

2. Concept paper on the development of a CHMP guideline on the non-clinical requirements to support early phase I clinical trials with pharmaceutical compounds. EMEA/CHMP/SWP/91850/2006. http://www. emea. europa.eu

3. Doroshow JH, Parchment RE. Oncologic phase 0 trials incorporating clinical pharmacodynamics: from concept to patient. Clin Cancer Res 2008; 14(12): 3658-63

4. Guidance for industry, investigators and reviewers on exploratory IND studies. FDA, January 2006. http://www. fda.gov

5. Guidance to the conduct of exploratory trials in Belgium. Working Document Federal Agency for Medicines and Health Products. http://www . afmps . be

6. Report of the international expert meeting on Exploratory clinical trial application and microdosing. 15 Sept 2007. BfArM (Germany)

7. ICH Topic M3 (R2) Note for guidance on non-clinical safety studies for the conduct of human clinical trials and marketing authorization for pharmaceuticals compounds. CHMP/ICH//286/95 July 2008 (draft in consultation).

8. Guidance on strategies to identify and mitigate risks for First-inHuman clinical trials with investigational medicinal products. EMEA/CHMP/SWP/28367/07 (19 July 2007). http://www. emea. europa.eu/pdfs/human/swp/2836707enfin.pdf
9. Guideline on the requirements to the chemical and pharmaceutical quality documentation concerning investigational medicinal products in clinical trials. EMEA, 2006. http: //www . emea . europa . eu

10. Bonnes pratiques de fabrication, Afssaps, décembre 2007. http://www afssaps.fr

11. Verbruggen A, Coenen H, Deverre JR, et al. Guideline to regulations for radiopharmaceuticals in early phase clinical trials in the EU. Eur J Nucl Med Mol Imaging 2008; 35: 2144-51

12. Essais de première administration à l'Homme, Afssaps, juillet 2006. http :// www . afssaps. fr

13. Guttierez M, Collyar D. Patient perspective on phase 0 clinical trials. Clin Cancer Res 2008; 14(12): 3689-91

14. Calvert AH, Plummer R. The development of phase I cancer trial methodologies: the use of pharmacokinetic and pharmacodynamic end points sets the scene for phase 0 cancer clinical trials. Clin Cancer Res 2008; 14(12): 3664-9

15. Murgo AJ, Kummar S, Rubinstein L, et al. Designing phase 0 cancer clinical trials. Clin Cancer Res 2008; 14(12): 3675-82

Correspondence and offprints: Alain Francillon, Novartis, Novartis, 2-4 rue Lionel Terray, BP 308, 92506 Rueil-Malmaison Cedex, France

E-mail: alain.francillon@novartis.com 